\section{BMJ Global Health}

\title{
Missing men with tuberculosis: the need to address structural influences and implement targeted and multidimensional interventions
}

\author{
Jeremiah Chikovore (D) , ${ }^{1}$ Madhukar Pai (D) ,2 Katherine Chisholm Horton, ${ }^{3,4}$ \\ Amrita Daftary (D) , ${ }^{5,6}$ Moses Kelly Kumwenda, ${ }^{7}$ Graham Hart, ${ }^{8}$ \\ Elizabeth Lucy Corbett ${ }^{3,7}$
}

\begin{abstract}
To cite: Chikovore J, Pai M, Horton KC, et al. Missing men with tuberculosis: the need to address structural influences and implement targeted and multidimensional interventions. BMJ Global Health 2020;5:e002255. doi:10.1136/ bmjgh-2019-002255
\end{abstract}

Handling editor Sanne Peters

Received 19 December 2019 Revised 5 April 2020 Accepted 7 April 2020
Check for updates

\section{(c) Author(s) (or their} employer(s)) 2020. Re-use permitted under CC BY. Published by BMJ.

For numbered affiliations see end of article.

\section{Correspondence to} Dr Jeremiah Chikovore; jchikovore@hsrc.ac.za

\section{ABSTRACT}

Tuberculosis (TB) is treatable but is the leading infectious cause of death worldwide, with men over-represented in some key aspects of the disease burden. Men's TB epidemiological scenario occurs within a wider public health and historical context, including their prior sidelining in health discussions. Differences are however noticeable in how some Western countries and high TB and HIV burden low and middle-income countries (LMIC) including in Africa have approached the subject(s) of men and health. The former have a comparatively long history of scholarship, and lately are implementing actions targeting men's health and wellness, both increasingly addressing multilevel social and structural determinants. In contrast, in the latter men have received attention primarily for their sexual practices and role in HIV and AIDS and gender-based violence; moreover, interventions, guided by the public health approach, have stressed short-term, measurable and medical goals. Debates and the limited available empirical literature on men's engagement with TB-related healthcare are nevertheless indicating need for a shift, within TB work with men in high burden LMICs towards, structural and multicomponent interventions.

\section{INTRODUCTION}

Tuberculosis (TB) is treatable but is the leading infectious cause of death worldwide with men over-represented in some key aspects of the disease burden. ${ }^{1}$ Globally in 2018, adult men (aged 15 years and older) constituted $55 \%$ (vs $31 \%$ for women) of TB deaths in HIV-negative people, and 49\% (vs $38 \%$ for women) of TB deaths in HIV-infected people. ${ }^{1}$ Men also accounted for $57 \%$ (vs $32 \%$ for women) of people who developed TB. ${ }^{1}$ Analysis of surveys implemented in African and Asian countries over the last two decades yielded a male-to-female (M:F) prevalence ratio of 2.21 (based on 56 surveys) for bacteriologically positive $\mathrm{TB}$, and 2.51 (based on 40 surveys) for smear-positive TB. ${ }^{2}$ Men's TB

\section{Summary box}

Despite being treatable, tuberculosis (TB) is the leading infectious cause of death worldwide.

- TB epidemiology reflects systematic inequities including an over-representation of men in some key poor indicators.

- The role of structural and multilevel factors in health status and behaviour, including for men, is increasingly acknowledged particularly in some Western settings.

- In high TB burden low-income settings, men's health and TB epidemiological situation have largely been overlooked, and men have been focused on mainly for their sexual practices and role in HIV/AIDS and gender-based violence.

- Addressing men's TB epidemiological situation requires acknowledging the complex determinants and implementing multifaceted interventions.

situation echoes their disadvantages in several areas of health, including poorer health services utilisation.

\section{MEN'S CONSISTENTLY POOR HEALTH OUTCOMES AND HEALTHCARE SERVICES UNDERUTILISATION} Despite gains in global health in recent decades, adult men lag behind women in various health indicators. In 2016, life expectancy surpassed 80 years in 57 and 10 countries for women and men, respectively. ${ }^{3}$ Indicating a widening gap, between 1970 and 2016, life expectancy increased globally by 13.5 years for men and 14.8 years for women, while the gap between men and women increased from 4.2 years to 5.5 years. ${ }^{4}$ Men also have poorer outcomes in HIV and AIDS where they delay testing and starting treatment; in addition, they have worse adherence and higher loss to follow-up when on 
Table 1 M:F sex ratios for incidence, notification and prevalence in selected regions and countries, and from analysis of surveys from different parts of the world; and contributions by sex to global TB notifications, cases and deaths

\begin{tabular}{ll}
\hline $\begin{array}{l}\text { Sex ratios for incidence, notification and prevalence in } \\
\text { selected regions/countries }\end{array}$ \\
\hline Incidence-all ages (2018) & M:F ratio \\
WHO Eastern Mediterranean Region & $1.3^{*}$ \\
WHO European Region & $2.0 \dagger$ \\
WHO West Pacific Region & $2.0 \dagger$ \\
Notification (2018) & M:F ratio \\
Global & 1.7 \\
WHO Eastern Mediterranean Region & $1.1^{*}$ \\
WHO West Pacific Region & $2.6 \dagger$ \\
Prevalence (from analysis of surveys from & M:F ratio \\
different parts of the world, 1993 - 2016) $\ddagger$ & \\
Bacteriologically confirmed TB & 2.21 \\
Smear-positive TB & 2.51 \\
\hline
\end{tabular}

Contributions by sex to global TB notifications, deaths and cases (2018)

\begin{tabular}{ll}
\hline Notifications & $\%$ \\
Men & 58 \\
Women & 34 \\
Adult TB deaths: HIV- uninfected & $\%$ \\
Men & 55 \\
Women & 31 \\
Adult TB deaths: HIV infected & $\%$ \\
Men & 49 \\
Women & 58 \\
Total TB cases & $\%$ \\
Men & 57 \\
Women & 32 \\
\hline
\end{tabular}

Source of data, except $\ddagger$ : WHO. ${ }^{1}$

*Lower value among $\mathrm{WHO}$ reporting regions

†Upper value among WHO reporting regions

$\ddagger$ Source of data. ${ }^{2}$

M:F, male-to-female; TB, tuberculosis.

treatment, and consequently higher chances of dying. ${ }^{5}$ HIV drives TB in high burden countries, and men's poorer outcomes in HIV and AIDS extend to TB. Table 1 shows sex differences in TB incidence, notification and prevalence. In 2018, the M:F ratio of incident TB cases for all ages in the different WHO regions ranged from 1.3 to 2.0 , and the M:F notification ratio was 1.7 globally. ${ }^{1}$ For the period $1970-2016$ the age-standardised TB incidence rate per 100000 people for men was nearly 1.8 times that of women ( $154.4 \mathrm{vs} 86.3$ ), and the TB mortality rate per 100000 at least twice higher in men than women (21.9 vs 10.8$){ }^{6}$

Explanations for the sex differences in TB rates are complex and subject of debate, but tend to include possible differences in biology, ${ }^{7-9}$ in risk-exposing behaviours and occupations,${ }^{10}$ in transmission dynamics, ${ }^{11}$ or in health services access, use, diagnostic and reporting practices. ${ }^{18}$ The accentuation of sex differences after childhood also suggests a role for environmental factors. ${ }^{12}$ Additionally, the prevalence-to-notification ratio is held to indicate a gap in diagnosis and reporting, ${ }^{2}$ and greater ratios among men imply women access diagnostic and treatment services more efficiently. Modelling work has further established that these gaps are significant, with delays from disease onset to treatment initiation 1 year longer for men than for women in Vietnam and Malawi. ${ }^{13}$ The sex differences have also persisted despite successes of the WHO-recommended strategy for controlling TB, DOTS (Directly Observed Treatment, Short Course), and interventions against HIV both driving declines in $\mathrm{TB}$, and despite higher HIV prevalence in women in countries with generalised HIV epidemics. ${ }^{2} 10$

Evidence from related HIV literature, and research from around the world consistently reporting men using health services less than women for most illnesses, supports a view of men accessing TB-related health services poorly. Among patients registered with general practice in the UK primary care, men's crude consultation rates were found to be $32 \%$ lower than for women. ${ }^{14}$ In Europe, sex differences in use of primary care services ranged from approximately 5\% in the Czech Republic and Austria to approximately $18 \%$ in Cyprus and Greece ${ }^{15}$ However, some argue women may be accessing services more but only during the reproductive years. ${ }^{16}$ Women's excess consultation for general health matters has also been questioned for relying on self-reported survey data and paying limited attention to underlying morbidity. ${ }^{14}$ For TB, it has also been suggested that while men delay seeking care, women face greater diagnostic barriers because they contact healthcare services more frequently, but reaching more easily accessible yet less qualified providers, and for symptoms not specific to TB. $^{17}$

\section{MEN IN PUBLIC HEALTH RESEARCH AND POLICY}

Men have traditionally been sidelined in public health due, in part, to early binary classification of sexes by biological attributes, which meant women were exclusively associated with reproduction and hence targeted in family planning and reproductive health research and policy. ${ }^{18}$ Later realisation that gender power and relational dynamics influenced the success of the programmes prompted efforts to include men. ${ }^{18}$ Towards the end of the last century, the unfolding HIV and AIDS epidemic particularly in Africa began to draw interest in men for their sexual practices, which were seen as fuelling disease. However, even when men were included in family planning, sexual and reproductive health, and HIV and AIDS efforts, the primary beneficiaries were still considered to be women. 
Differences are observable in how some Western countries and low and middle-income countries (LMIC), particularly the high TB and HIV burden, have handled the subject(s) of men and health. In some Western countries, men, masculinity and health have been the focus of fairly considerable scholarly work over the last odd half century. During this time, analyses generally moved from positivist and essentialist concepts (which stress uniformity within genders, and the role of biological or innate psychological traits in behaviour) towards ecological and social constructionist concepts (which consider historical and contemporary forces, context, and race, class and gender relations in explaining behaviour). ${ }^{19-21}$ Being broad and encompassing, social constructionism and related constructs have in recent decades informed substantial research on men's behaviours and health. Specific topics where they have been applied in the West include managerial settings, ${ }^{22} 23$ schooling and boys' achievement ${ }^{24}$ and participation in activities such as dance, ${ }^{25}$ perceptions of women in soccer, ${ }^{26} \mathrm{HIV}$ and AIDS, and specific male diseases such as prostrate and testicular cancer.

On the African continent, on the other hand, masculinity debates are relatively incipient. A few countries, principally South Africa, have had a longer scholarly history, addressing mainly men's sexuality and risktaking behaviours, and gender-based and other forms of violence. Some of the earlier research aimed to document men's behaviour and attitudes, generally using assumptions of linear causation. ${ }^{27}$ From around the turn of the century, masculinity scholarship increased rapidly, the bulk now also influenced by ecological frameworks. This work has discussed the role of apartheid and colonial administration-related labour migration and mining economies, breakdown in social and communal relationships, and institutions such as factories, mines, prisons, farms and schools in cultivating various versions of masculinities. ${ }^{28-36}$

Policies and interventions appear to have lagged behind globally, although lately some Western countries seem to be making greater progress compared with LMICs including in Africa. In the USA, concern was raised as early as the ' 60 s regarding the silence about men's health in public conversations, including presidential campaigns, despite their worse life expectancy and engagement with health services. ${ }^{37}$ Initiatives on men's health in some Western countries only took off around the turn of the century, often driven at regional or local level, or by non-government organisations. ${ }^{38}$ Those by central governments struggled to survive, partly because they were interrupted when administrations changed. ${ }^{38}$

What is believed to be the world's first policy on men's health was thus only published by Ireland in 2009, with countries such as Australia-with a long history of engaging with men's health issues-also making noticeable progress. ${ }^{38}$ Presently, few countries (namely Ireland, Brazil, Iran and Australia) have national health policies or strategies specifically addressing men. ${ }^{39}$ Canada has formally identified gender equity as a goal of health policy, and England and Wales built momentum from the establishment of the Men's Health Forum by the Royal College of Nursing in $1994 .{ }^{38}$ The first specialist university department on men's health was established at Leeds Metropolitan University in 2004, and in Scotland, the first primary care centre dedicated to improving men's health was set up in 2001. National Men's Health weeks, men's health organisations (namely the European Men's Health Forum, Nordic Men's Health Network, Men's Health Network in the USA, and Health Advice for Australian Men, and Men's Health, in Australia), marathon events and conferences are being implemented across the Western world, although some countries are trailing behind. ${ }^{38}$ In 2011, the European Union commissioned The State of Men's Health in Europe report, and recently, the region introduced a men's health strategy, which focuses on social determinants of health and advocates for gender responsive health services. ${ }^{40}$

Women's heightened social, economic, and health vulnerability, limited health access, and power disadvantage, which take unique forms in high TB and HIV burden LMICs, have seen efforts there being directed towards women-centred initiatives, and gender vulnerability being equated with women in TB research and policy. ${ }^{41-51}$ In these settings, particularly in parts of Africa where HIV drives TB, men have received attention mainly in relation to their sexual practices and role in the related HIV and AIDS epidemic and gender-based violence. Services for HIV and AIDS were also initially linked to maternal and child health, ${ }^{52}$ with the result, for men, attending health services was experienced as stigmatising. Implementation activities in these settings also tended to pursue quantitatively measurable, shortterm or primarily clinical outcomes. ${ }^{53}$ They additionally sought to change men's attitudes through activities such as mass media campaigns, education, community workshops, engagement of traditional leaders ${ }^{545}$ and involvement of men in participatory activist fora. ${ }^{56}$

\section{WHY DO MEN NOT ENGAGE WITH HEALTHCARE SERVICES?}

A diverse literature that straddles qualitative, survey, modelling, and non-fiction work, different world regions and several decades, and various social and health topics from a range of theoretical positions, highlights key determinants of men's use of health services. The determinants can be (re)framed within gender relational theory, an approach within the social constructionist paradigm and which acknowledges how women and femininity, and men and masculinity shape each other and society at large, and simultaneously locates gender relations within wider social, political, historical and economic contexts. ${ }^{20} 57$

The present-day layout, staffing and interaction of primary health facilities with men can be seen as part remnant of how primary healthcare was historically modelled around maternal and child health. Men report 
feeling alienated at primary care facilities ${ }^{58} 59$ which are normatively considered places for women and children ${ }^{60}$ but also felt as not serving men in sensitive and empathetic ways. Men also fear opportunity losses should they pursue activities such as seeking healthcare, which in their view may not have evident or immediate economic value. Anxieties about being publicly chastised at health facilities and blamed for causing their own illness and that of women related to them are further deterrents. ${ }^{56}$

Outside the healthcare system, men are deterred from seeking healthcare because this behaviour is experienced or seen as a weakness. This is significant where men who display lack of control face ridicule and social devaluation from peers, women and even children. ${ }^{6162}$ Men thus consciously or unwittingly suppress illness avoiding or compensating for appearing to be feminine or not in control. One way they do this is by deeming themselves naturally stronger physically than women. ${ }^{6364}$ They also overlook illness while striving to fulfil duties of providing for and inspiring families, a responsibility many nevertheless increasingly find hard to achieve. ${ }^{6365}$

On the African continent the male breadwinner role emerged as a creation from the colonial past ${ }^{66}$ with the entire colonial process resulting in "missing men who occupy marginal positions within households and communities $^{67}$ (p 19). In South Africa the segregationist policy of apartheid dispossessed non-White communities of land, and their labour was appropriated over decades while they were condemned to humiliatingly bleak lifetime opportunities. Movement and residence restrictions resulted in difficult living conditions for families, and communities in which poor social connectedness, unemployment, ethnic tensions, exchange sex and gangsterism prevailed. Selective application of justice and policing brewed resentment and violence within communities and against the system. Many men, on whom the expectation to earn cash had fallen, struggled to raise money to meet their provider roles or other status-conferring needs such as marriage.

Failure to achieve the socially valued masculine grade prompts in men intensified efforts to demonstrate possession of the attributes, or a resort to more accessible versions, and pursuit of these in extremis no matter the health implications. ${ }^{68}$ A systematic review on healthcare seeking for depression found that, in addition to engaging in other 'escape' behaviours, namely risktaking, anger-fuelled conflict, and increased work hours, men used short-term strategies of turning to substance and alcohol use. ${ }^{69}$ They additionally concealed distress, re-emphasised strength and resorted to performing masculinity publicly or adhering to traditional concepts of masculinity. ${ }^{69}$ Depression, alcoholism, danger and death thus became common in non-White communities in South Africa ${ }^{62}$ and more widely across colonial Southern Africa's mining and urban communities, ${ }^{28}$ and formed the context in which men leant to face and inflict danger, and hence also to suppress or overlook it.

\section{WHY DO MEN NOT ENGAGE WITH TB CARE?}

The prior focus on women in TB research, policy and funding has meant little research exists on men's TB care access barriers, and most of this has come out of the African continent. This literature, together with related studies on HIV, gender and masculinity, and healthcare seeking illuminates men's TB healthcare access barriers. Some barriers seem or are indeed similar for men and women: it is nevertheless critical to understand from a gendered lens whether and how they have different implications for different genders.

Fear and anxiety are, for example, well reported with regard to engagement with TB (and HIV) care, but assume nuanced forms through a masculinity-mediated lens. Men are reported in studies delaying seeking healthcare for cough due to fear, or avoiding a possible diagnosis, of TB which is considered 'serious' or confirmatory of HIV. $^{60}{ }^{70-72}$ The link between cough, TB, HIV and highlylikely death in high HIV burden settings fuels stigma of cough and TB at community and family levels. ${ }^{173-75}$ Resulting fears, ${ }^{70} 76$ while affecting both women and men, take special forms when they intersect with masculinity expectations for men.

An expectation to display control over their lives explains part of men's fears and anxieties. TB is perceived and experienced as a virulent disease that hampers independent functioning, and whose treatment drains financial resources. ${ }^{63657176}$ In turn, this interferes with socialisation, alcohol use and sexual activity ${ }^{6070} 71$ accentuating anxieties about being investigated and/or confirmed with disease. Similar threats to socially valued concepts of masculinity are reported for HIV and AIDS. ${ }^{34} 77-79$

Men also fear being seen at primary care facilities, whose association with women potentially attracts such unwanted labels as being 'lesser than men' or having an exceptional illness. ${ }^{60}$ They thus regularly infer about their own health from outcomes of investigations on their women spouses, who also have more connection to primary care and HIV testing services. ${ }^{80}$

Anxieties even where health services are available free of charge, and when antiretroviral therapy has improved longevity and quality of life with TB or HIV, testify to the complex dynamics surrounding men's TB-related healthcare seeking. Men must deal with unemployment or insecure or low-paying jobs, contend with erosion of male privilege from efforts to promote gender equality, and manage various intersecting forms of marginalisation in their daily lives. ${ }^{6165}$ Scarce employment and limited job security mean, for example, those who display signs of ill health or are confirmed with TB are at risk of losing their jobs. ${ }^{65}{ }^{76}$ Simultaneously society, other men and women put pressure on men to display strength, good health, and self-sufficiency, and ability to provide basic and consumer needs to their families. ${ }^{63} 65$ Being ill and physically constrained, or merely seeking healthcare, or acknowledging minor or early-stage illness can thus entail a special form of stigma for men. ${ }^{6365}$ Furthermore, drug, transport and food costs while seeking care for TB 
in LMICs, ${ }^{7476}$ exacerbated when health system challenges necessitate multiple visits, while not specific to men may compel them to relegate healthcare in favour of livelihood needs.

Those undertaking to be investigated encounter at health facilities long waiting times or opening hours unaccommodative of their schedules, ${ }^{70}$ or jostle in queues with women and children for attention. ${ }^{76}$ Delays at healthcare facilities affect men differently where they are designated primary breadwinner, employment is scarce with limited social protection, and any time away from 'working' means huge opportunity costs. Spending time waiting to be served may be experienced as demeaning by men, who must consistently publicly demonstrate active pursuit of earning opportunities. These experiences for men are worsened by frustrated and overworked health services staff acting discourteously, communicating poorly about algorithms and belittling or blaming men for allegedly causing themselves to be ill and burdening health systems. ${ }^{60} 65$ Unfriendly healthcare services are widely reported and affect all groups of patients. Still, public humiliation likely elicits specific feelings in men, who visit health facilities less and would feel emasculated before women and children, whom they ordinarily seek to lead and protect.

These complexly intersecting factors trigger responses to illness such as waiting until symptoms are unbearable or life-threatening. Waiting can entail outright avoidance or putting off of healthcare seeking ${ }^{606369}$; or pursuit of distractions, possibly ones that reaffirm valued masculine traits, like working intensively or socialising and drinking excessively to fend off illness. ${ }^{60} 63$ Studies have described men's preference for using traditional medicine and alternative forms of treatment, and for seeking healthcare first from places other than where they can be diagnosed formally. ${ }^{74780}$ In avoiding healthcare, men may use socially appropriate alibis such as being unable to spare time owing to work demands. ${ }^{65}$ Illness responses often taken as evidence of men's stoicism and irresponsibility are likely outcomes of interactional dynamics involving structural factors and social roles. Men's role as bread earners also forces some to seek 'fast cures' from sources, often private (eg, drugstores, unqualified practitioners, traditional healers) that offer highly variable or poor quality care. ${ }^{81}$

\section{FINDING MEN WITH TB WHO ARE MISSED BY PROGRAMMES}

Management of TB (and HIV and AIDS) in LMICs has relied on WHO's public health approach. ${ }^{82}$ This approach stresses standardised and simplified treatment protocols, decentralised service delivery to reach large numbers of people through primarily the public sector, and working with lower level healthcare workers to deliver care, ${ }^{82}$ and in some programmes involves backing of free healthcare services to the public. However, the historical and more recent declines in TB burden largely happened alongside improvements in socioeconomic indicators. ${ }^{83}$ The
End TB strategy, ${ }^{84}$ Moscow Declaration to End TB, and United Nations High-Level Meeting (UNHLM) on TB are among the growing voices advocating for anti-TB efforts that fall within the broader sustainable development agenda, tackle multidimensional determinants of health, strengthen health services delivery, enhance private sector engagement and quality and move to universal healthcare and active case finding, among others. ${ }^{185}$

In high TB and HIV burden LMICs, many men's health-related behaviours and outlook are engendered within structurally conditioned parameters. The complex influences particularly on their TB-related healthcare seeking call for analyses and interventions that consider in context men's role expectations, means available for pursuing these, and implications of failure or its threat. Structural conditions and gendered interactional dynamics imply men are discouraged from displaying weakness and acknowledging illness, face opportunity and real costs from illness incapacitation and healthcare seeking, and encounter unaccommodating and emasculating health services. Interventions, guided by ecological and intersectionality frameworks, need to straddle policies at international and national levels, structural and social actions at local, national, societal and community levels, and behaviour and knowledge at interpersonal and personal microlevels. (For an illustrative draft intervention framework, see ref ${ }^{86}$.)

Exemplifying high-level global action, in 2018 the UNHLM on TB called for recognising the higher TB prevalence in men. In the same year, the WHO advocated for enhancing men's access to and use of health services, ${ }^{87}$ while the Special Programme for Research and Training in Tropical Diseases revealed plans to expand training and research support on gender, and held a meeting of experts with masculinities and TB on the agenda. In its recent annual meetings, the Union World Conference on Lung Health has also featured presentations and seminars on men and TB. On the HIV and AIDS front, the International AIDS Society included several sessions and a preconference forum on men at its 2019 scientific conference.

Beyond developments taking place internationally, interventions to engage men in $\mathrm{TB}$ need to include social protection mechanisms, promotion of wellness in and through men's different work settings ${ }^{40}$ and awareness promotion including highlighting the importance of early diagnosis and treatment. ${ }^{88}$ Equally, the preparedness of public and private healthcare services to accommodate men (and women) based on their roles, circumstances and needs-in line with the ethos of client-centred care $^{85}$ - should be evaluated and supported. Engagement of private and informal sectors, in particular improvement of quality of $\mathrm{TB}$ care in these sectors, is critical to helping find missing patients with TB including men. ${ }^{89} 90$ Flexible opening times, mobile services, algorithms reducing waiting times, male-friendly spatial arrangements and healthcare staff trained in male sensitivity are all potential interventions to explore or 
implemented as suits context. ${ }^{86}$ Examples of tailored interventions that have indicated success include workshops for men implemented as part of the gender-based violence response, ${ }^{91}$ and reaching men in HIV testing trials through settings such as bars, churches and workplaces, and using mobile testing services. ${ }^{92}$ These strategies fit well demands of men's TB epidemiological situation and can be adapted while retaining sight on the value of multieffect and synergistic actions to address complexities of men's TB care access.

\section{CONCLUSION}

Men's disproportionate TB epidemiological burden and poor healthcare access reflect a broader pattern of suboptimal engagement with health services, which is barely helped by their absence in funding and policy. Greater attention to men, with research and interventions addressing the range and complexity of their TB and general healthcare engagement determinants, and supported by robust social science research to illuminate contextual and relational dynamics, is needed. This does not denote turning attention from women or seeing them as not vulnerable: women's special vulnerability to TB and social and structural injustices ${ }^{93}$ is well documented and necessitates their continued prioritisation. Rather, it reminds how gender affects women and men and their experiences of disease predominantly differently, with wider public health ramifications.

\section{Author affiliations}

${ }^{1}$ Human and Social Capabilities Research Division, Human Sciences Research Council, Durban, South Africa

${ }^{2}$ McGill Global Health Programme \& McGill International TB Centre, McGill University, Montréal, Ontario, Canada

${ }^{3}$ Department of Clinical Research, London School of Hygiene and Tropical Medicine, London, UK

${ }^{4}$ Department of Infectious Disease Epidemiology, London School of Hygiene and Tropical Medicine, London, UK

${ }^{5}$ Dahdaleh Institute of Global Health Research, York University, Toronto, Ontario, Canada

${ }^{6}$ Centre for the Aids Programme of Research in South Africa (CAPRISA), University of KwaZulu Natal, Durban, South Africa

${ }^{7}$ Malawi-Liverpool Wellcome Trust Clinical Research Programme, Blantyre, Malawi

${ }^{8}$ School of Life and Medical Sciences, University College London, London, UK

Twitter Jeremiah Chikovore @jerrychikovore, Madhukar Pai @paimadhu and Amrita Daftary @DaftaryAmrita

Contributors Conceived the manuscript: JC, MP, GH, ELC. Drafted the manuscript: JC. Contributed scientifically and revised the manuscript: all authors.

Funding JC has previously received funding from the Wellcome Trust (Grant No WT085411MA). KCH is funded by the European Research Council Starting Grant (Action № 757699).

Competing interests None declared.

Patient consent for publication Not required.

Provenance and peer review Not commissioned; externally peer reviewed.

Data availability statement There are no data in this work.

Open access This is an open access article distributed in accordance with the Creative Commons Attribution 4.0 Unported (CC BY 4.0) license, which permits others to copy, redistribute, remix, transform and build upon this work for any purpose, provided the original work is properly cited, a link to the licence is given, and indication of whether changes were made. See: https://creativecommons.org/ licenses/by/4.0/.

\section{ORCID iDs}

Jeremiah Chikovore http://orcid.org/0000-0002-4910-6952

Madhukar Pai http://orcid.org/0000-0003-3667-4536

Amrita Daftary http://orcid.org/0000-0003-2275-3540

\section{REFERENCES}

1 WHO. Global tuberculosis report 2019. Geneva: World Health Organisation, 2019.

2 Horton KC, MacPherson P, Houben RMGJ, et al. Sex differences in tuberculosis burden and notifications in low- and middle-income countries: a systematic review and meta-analysis. PLoS Med 2016;13:e1002119.

3 World Bank. Life expectancy at birth: world bank, 2019. Available: https://data.worldbank.org/indicator/sp.dyn.le00.in [Accessed 22 Oct 2019].

4 Wang $\mathrm{H}$, Abajobir $\mathrm{AA}$, Abate $\mathrm{KH}$, et al. Global, regional, and national under-5 mortality, adult mortality, age-specific mortality, and life expectancy, 1970-2016: a systematic analysis for the global burden of disease study 2016. Lancet 2017;390:1084-150.

5 UNAIDS. Reaching out to men and boys: addressing a blind spot in the response to HIV. Geneva: UNAIDS, 2017.

6 GBD Tuberculosis Collaborators. The global burden of tuberculosis: results from the global burden of disease study 2015. Lancet Infect Dis 2018;18:261-84.

7 Salie M, Daya M, Lucas LA, et al. Association of Toll-like receptors with susceptibility to tuberculosis suggests sex-specific effects of TLR8 polymorphisms. Infect Genet Evol 2015;34:221-9.

8 Hertz D, Schneider B. Sex differences in tuberculosis. Semin Immunopathol 2019;41:225-37.

9 Yates TA, Atkinson SH. Ironing out sex differences in tuberculosis prevalence. Int J Tuberc Lung Dis 2017;21:483-4.

10 Marçôa R, Ribeiro Al, Zão I, et al. Tuberculosis and gender - factors influencing the risk of tuberculosis among men and women by age group. Pulmonology 2018;24:199-202.

11 Martinez AN, Rhee JT, Small PM, et al. Sex differences in the epidemiology of tuberculosis in San Francisco. Int J Tuberc Lung Dis 2000;4:26-31.

12 Zucs P, Dara M, Pd C, et al. Tuberculosis surveillance and monitoring in Europe, 2018. 2016 data. Stockholm: European Centre for Disease Prevention and Control, 2018.

13 Horton KC, Sumner T, Houben RMGJ, et al. A Bayesian approach to understanding sex differences in tuberculosis disease burden. Am J Epidemiol 2018;187:2431-8.

14 Wang $\mathrm{Y}$, Hunt K, Nazareth I, et al. Do men consult less than women? An analysis of routinely collected UK general practice data. BMJ Open 2013:3:e003320.

15 Malcher G. The state of men's health in Europe. BMJ 2011;343:d7054.

16 Hawkes S, Buse K. Gender and global health: evidence, policy, and inconvenient truths. Lancet 2013;381:1783-7.

17 van den Hof S, Najlis CA, Bloss E, et al. A systematic review on the role of gender in tuberculosis control. The Hague: KNCV Tuberculosis Foundation, 2010.

18 Ahlberg BM. A critical review of the family planning programmes with special reference to Sub-Sahara Africa. Stockholm: Karolinska Institutet, 1989.

19 Carrigan T, Connell B, Lee J. Toward a new sociology of masculinity. Theory Soc 1985;14:551-604.

20 Connell R, Gender CR. Gender, health and theory: conceptualizing the issue, in local and world perspective. Soc Sci Med 2012;74:1675-83.

21 Barkow JH, Cosmides L, Tooby J. The adapted mind: evolutionary psychology and the generation of culture. USA: Oxford University Press, 1995.

22 Kerfoot D, Whitehead S. 'Boys own'stuff: masculinity and the management of further education. Sociol Rev 1998;46:436-57.

23 Oudenhoven JP, Mechelse L, Dreu CKW. Managerial conflict management in five European countries: the importance of power distance, uncertainty avoidance, and masculinity. Appl Psychol 1998:47:439-55.

24 Martino W, Meyenn B. What about the boys? Issues of masculinity in schools. Buckingham: Open University Press, 2001.

25 Dance FA. Masculinity and teacher education. British Journal of Physical Education 1991;22:31-5. 
26 Caudwell J. Women's football in the United Kingdom: Theorizing gender and unpacking the butch lesbian image. J Sport Soc Issues 1999;23:390-402.

27 Piotrow PT, Kincaid DL, Hindin MJ, et al. Changing men's attitudes and behavior: the Zimbabwe male motivation project. Stud Fam Plann 1992;23:365-75.

28 Van Onselen C. Chibaro: African mine labour in southern Rhodesia, 1900-1933. London: Pluto Press, 1980.

29 Packard RM. White plague, black labor. California: University of California Press, 1989.

30 Silberschmidt M. 11. masculinities, sexuality and socio-economic change in rural and urban East Africa. Re-thinking sexualities in Africa 2004;233.

31 Chikovore J, Lindmark G, Nystrom L, et al. The hide-and-seek game: men's perspectives on abortion and contraceptive use within marriage in a rural community in Zimbabwe. J Biosoc Sci 2002;34:317-32.

32 Shefer T, Strebel A, Wilson T, et al. The social construction of sexually transmitted infections (STIs) in South African communities. Qual Health Res 2002;12:1373-90.

33 Barker G, Ricardo C. Young men and the construction of masculinity in sub-Saharan Africa: implications for HIVIAIDS, conflict, and violence. Washington, DC: World Bank, 2005.

34 Brown J, Sorrell J, Raffaelli M. An exploratory study of constructions of masculinity, sexuality and HIV/AIDS in Namibia, southern Africa. Cult Health Sex 2005;7:585-98.

35 Hunter M. Cultural politics and masculinities: Multiple-partners in historical perspective in KwaZulu-Natal. Cult Health Sex 2005;7:389-403

36 Morrell R, Jewkes R, Lindegger G. Hegemonic masculinity/ masculinities in South Africa: culture, power, and gender politics. Men Masc 2012:15:11-30.

37 Elder K, Griffith DM. Men's Health: Beyond Masculinity. Am J Public Health 2016;106:1157-57.

38 EMHF. Men's health around the world. Brussels: European Men's Health Forum, 2009.

39 The Lancet. Raising the profile of men's health. Lancet 2019;394:1779.

40 Baker P. A European men's health strategy: here at last. Trends Urology \& Men Health 2019;10:21-4.

41 Long $\mathrm{NH}$, Johansson $\mathrm{E}$, Lönnroth $\mathrm{K}$, et al. Longer delays in tuberculosis diagnosis among women in Vietnam. Int J Tuberc Lung Dis 1999;3:388-93.

42 Long $\mathrm{NH}$, Johansson $\mathrm{E}$, Diwan VK, et al. Fear and social isolation as consequences of tuberculosis in Vietnam: a gender analysis. Health Policy 2001;58:69-81.

43 Needham DM, Foster SD, Tomlinson G, et al. Socio-economic, gender and health services factors affecting diagnostic delay for tuberculosis patients in urban Zambia. Trop Med Int Health 2001;6:256-9.

44 Thorson A, Diwan VK. Gender inequalities in tuberculosis: aspects of infection, notification rates, and compliance. Curr Opin Pulm Med 2001;7:165-9.

45 Yamasaki-Nakagawa M, Ozasa K, Yamada N, et al. Gender difference in delays to diagnosis and health care seeking behaviour in a rural area of Nepal. Int $J$ Tuberc Lung Dis 2001;5:24-31.

46 Atre SR, Kudale AM, Morankar SN, et al. Cultural concepts of tuberculosis and gender among the general population without tuberculosis in rural Maharashtra, India. Trop Med Int Health 2004:9:1228-38.

47 Austin JF, Dick JM, Zwarenstein M. Gender disparity amongst TB suspects and new TB patients according to data recorded at the South African Institute of medical research laboratory for the Western Cape region of South Africa. Int J Tuberc Lung Dis 2004;8:435-9.

48 Eastwood SV, Hill PC. A gender-focused qualitative study of barriers to accessing tuberculosis treatment in the Gambia, West Africa. Int $J$ Tuberc Lung Dis 2004;8:70-5.

49 Cambanis A, Yassin MA, Ramsay A, et al. Rural poverty and delayed presentation to tuberculosis services in Ethiopia. Trop Med Int Health 2005;10:330-5.

50 Horton KC, White RG, Houben RMGJ. Systematic neglect of men as a key population in tuberculosis. Tuberculosis 2018;113:249-53.

51 Mitchell E. Gender trouble for tuberculosis. Global Fund Observer 2020;2014:6-9.

52 Auld AF, Shiraishi RW, Mbofana F, et al. Lower levels of antiretroviral therapy enrollment among men with HIV compared with women - 12 countries, 2002-2013. MMWR Morb Mortal Wkly Rep 2015;64:1281-6.
53 Kippax S, Holt DM. The state of social and political science research related to HIV: a report for the International AIDS Society. Geneva: International AIDS Society, 2009.

54 Stern E, Pascoe L, Shand T, et al. Lessons learned from engaging men in sexual and reproductive health as clients, partners and advocates of change in the Hoima district of Uganda. Cult Health Sex 2015;17:190-205.

55 Seedat M, Van Niekerk A, Jewkes R, et al. Violence and injuries in South Africa: prioritising an agenda for prevention. Lancet 2009:374:1011-22.

56 Mills EJ, Beyrer C, Birungi J, et al. Engaging men in prevention and care for HIV/AIDS in Africa. PLoS Med 2012;9:e1001167.

57 Lohan M. How might we understand men's health better? Integrating explanations from critical studies on men and inequalities in health. Soc Sci Med 2007;65:493-504.

58 Lichtenstein B. Caught at the clinic African American men, stigma, and STI treatment in the deep South. Gend Soc 2004;18:369-88.

59 Leichliter JS, Paz-Bailey G, Friedman AL, et al. 'Clinics aren't meant for men': Sexual health care access and seeking behaviours among men in Gauteng province, South Africa. SAHARA-J: Journal of Social Aspects of HIVIAIDS 2011;8:82-8.

60 Mavhu W, Dauya E, Bandason T, et al. Chronic cough and its association with TB-HIV co-infection: factors affecting helpseeking behaviour in Harare, Zimbabwe. Trop Med Int Health 2010;15:574-9.

61 Steinberg J. Sizwe's test: a young man's journey through Africa's AIDS epidemic. Simon and Schuster, 2008.

62 Steinberg J. One day in Bethlehem. Johannesburg: Jonathan Ball Publishers, 2019.

63 Chikovore J, Hart G, Kumwenda M, et al. Control, struggle, and emergent masculinities: a qualitative study of men's care-seeking determinants for chronic cough and tuberculosis symptoms in Blantyre, Malawi. BMC Public Health 2014:14:1053.

64 White A, McKee M, Richardson N, et al. Europe's men need their own health strategy. BMJ 2011;343:d7397.

65 Chikovore J, Hart G, Kumwenda M, et al. 'For a mere cough, men must just chew Conjex, gain strength, and continue working': the provider construction and tuberculosis care-seeking implications in Blantyre, Malawi. Glob Health Action 2015;8:26292.

66 Morrell R. Of boys and men: masculinity and gender in southern African studies. J South Afr Stud 1998;24:605-30.

67 Cornwall A. Missing Men? Reflections on Men, Masculinities and Gender in GAD. IDS Bull 2000;31:18-27.

68 Kimmel MS. Masculinity as homophobia: fear, shame, and silence in the construction of gender identity. In: Race, class, and gender in the United States: an integrated study, 2004: 81-93.

69 Seidler ZE, Dawes AJ, Rice SM, et al. The role of masculinity in men's help-seeking for depression: a systematic review. Clin Psychol Rev 2016;49:106-18.

70 Miller C, Huston J, Samu L, et al. 'It makes the patient's spirit weaker': tuberculosis stigma and gender interaction in Dar ES Salaam, Tanzania. Int J Tuberc Lung Dis 2017;21:42-8.

71 Chikovore J, Hart G, Kumwenda M, et al. Tb and HIV stigma compounded by threatened masculinity: implications for TB health-care seeking in Malawi. Int $J$ Tuberc Lung Dis 2017;21:26-33.

72 Kumwenda M, Desmond N, Hart G, et al. Treatment-seeking for tuberculosis-suggestive symptoms: a reflection on the role of human agency in the context of universal health coverage in Malawi. PLoS One 2016;11:e0154103.

73 Romanowski K, Baumann B, Basham CA, et al. Long-term all-cause mortality in people treated for tuberculosis: a systematic review and meta-analysis. Lancet Infect Dis 2019;19:1129-37.

74 Nliwasa M, MacPherson P, Mukaka M, et al. High mortality and prevalence of HIV and tuberculosis in adults with chronic cough in Malawi: a cohort study. Int J Tuberc Lung Dis 2016;20:202-10.

75 Chimbatata NBW, Zhou C-M, Chimbatata CM, et al. Post-2015, why delay to seek healthcare? perceptions and field experiences from TB healthcare providers in northern Malawi: a qualitative study. Infect Dis Poverty 2017;6:60.

76 GCTA. Men and stigma: conversations of resilience in the war against TB. e-Book: global coalition of TB activists 2019.

77 Skovdal M, Campbell C, Madanhire C, et al. Masculinity as a barrier to men's use of HIV services in Zimbabwe. Global Health 2011;7:13-14.

78 Colvin CJ, Robins S, Leavens J. Grounding "responsibilisation talk": masculinities, citizenship and HIV in Cape Town, South Africa. J Dev Stud 2010;46:1179-95.

79 Lynch I, Brouard PW, Visser MJ. Constructions of masculinity among a group of South African men living with HIV/AIDS: reflections on resistance and change. Cult Health Sex 2010;12:15-27. 
80 Chikovore J, Gillespie N, McGrath N, et al. Men, masculinity, and engagement with treatment as prevention in KwaZulu-Natal, South Africa. AIDS Care 2016;28:74-82.

81 Daniels B, Kwan A, Pai M, et al. Lessons on the quality of tuberculosis diagnosis from standardized patients in China India, Kenya, and South Africa. J Clin Tuberc Other Mycobact Dis 2019;16:100109.

82 Gilks CF, Crowley S, Ekpini R, et al. The WHO public-health approach to antiretroviral treatment against HIV in resource-limited settings. Lancet 2006;368:505-10.

83 Trauer JM, Dodd PJ, Gomes MGM, et al. The importance of heterogeneity to the epidemiology of tuberculosis. Clin Infect Dis 2019;69:159-66.

84 WHO. Gear up to end TB: introducing the end TB strategy. Geneva: World Health Organization, 2015.

85 Reid MJA, Arinaminpathy N, Bloom A, et al. Building a tuberculosisfree world: the Lancet Commission on tuberculosis. Lancet 2019;393:1331-84.

86 Chikovore J, Hart G, Kumwenda M, et al. The influence of masculinity on care seeking for TB. Liverpool: 47th World Union Conference on Lung Health, 2016.

87 WHO. Global tuberculosis report 2018. Geneva: World Health Organisation, 2018.
88 Monk EJM, Kumwenda M, Nliwasa M, et al. Factors affecting tuberculosis health message recall 2 years after active case finding in Blantyre, Malawi. Int $J$ Tuberc Lung Dis 2018;22:1007-15.

89 WHO. Public-private mix for TB prevention and care: a roadmap. Geneva: World Health Organization, 2018.

90 Kruk ME, Gage AD, Joseph NT, et al. Mortality due to lowquality health systems in the universal health coverage era: a systematic analysis of amenable deaths in 137 countries. Lancet 2018;392:2203-12.

91 Smith C. How communities are addressing violence against women in South Africa: Sonke Gender Justics [cited 20193 April 2020], 2019. Available: https://genderjustice.org.za/news-item/howcommunities-are-addressing-violence-against-women-in-southafrica/ [Accessed 27 Nov 2019].

92 Hensen B, Taoka S, Lewis JJ, et al. Systematic review of strategies to increase men's HIV-testing in sub-Saharan Africa. AIDS 2014;28:2133-45.

93 Krishnan L, Akande T, Shankar AV, et al. Gender-related barriers and delays in accessing tuberculosis diagnostic and treatment services: a systematic review of qualitative studies. Tuberc Res Treat 2014;2014:1-14 